\title{
New information about the mechanism of oil displacement from productive reservoirs using flow control technologies
}

\author{
Rustam Mukhametshin ${ }^{1,2}$, Gulnara Kvon ${ }^{3}$ \\ ${ }^{1}$ Ural State Mining University, Department of Lithology and Geology of Fossil Fuels, 620144, 30, \\ Kuibyshev st., Ekaterinburg, Russia \\ ${ }^{2}$ Kazan Federal University, Department of Oil and Gas Geology, 420008, 18, Kremlevskaya st., \\ Kazan, Russia \\ ${ }^{3}$ Ural State University of Economics, Department of Regional, Municipal Economics and \\ Management 620144, 62, 8 Marta st., Ekaterinburg, Russia
}

\begin{abstract}
The article is devoted to improving the efficiency of methods application to increase oil recovery of deposits that are at the final stage of development. This stage is characterized by a high degree of waterlogging of reservoirs and extracted products. From a wide range of chemical methods for increasing oil recovery in Russian oil deposits, flow-regulating (flow-deflecting) technologies have become widespread. The article analyzes the results of purposeful use of thickened water for the completion of reserves of already flooded sandstone layers. Experimental studies were performed on two specially created five-point elements in the experimental sections of the Romashkinskoye deposit. To monitor the process of lowviscosity and high-viscosity oil displacement the following methods were used: a) intake, monitoring and production wells, in which the interval of productive horizons are lined with fiberglass pipes; b) method of highfrequency resistivity (technology of "VNIIneftepromgeophysics" Institute). The studies performed in the monitoring mode showed that, along with the increase in reservoir coverage by flooding at the macro level, there is also a displacement of part of the capillary-trapped oil in the already flooded layers' intervals, that is, at the level of micro-uniformity of the porous medium. The paper concludes on the effectiveness of using flow-regulating technologies in conditions of high water availability of development objects. Keywords: oil-bearing sand formation, flooding, flow-regulating technology, pilot site, induction method, monitoring, oil displacement mechanism.
\end{abstract}

\section{Introduction}

Large oil deposits in the Ural-Volga region and Western Siberia (Romashkinskoye, Samotlorskoye, Novo-Elkhovskoye, Tuymazinskoye, etc.), operated for 50-70 years and, in the figurative expression of V.D. Lysenko and V.I. Greifer, which define the "face" of the industry, has already entered the final stage of development about 30 years ago due to the significant depletion of active reserves. At the same time, the waterlogged layers of the largest deposits contain a significant share of recoverable oil reserves, which provides about 
half of the current production. Experts' estimates show that an increase in the final oil recovery factor (ORF) by only one point can provide an increase in annual production equal to 50-55 million tons. However, the remaining oil in reservoirs with a water cut of more than $90 \%$ is one of the most complex categories of hard-to-recover reserves, since it is the result of shortcomings and omissions in the development system accumulated during the previous stages of development [1].

\section{Materials and methods}

According to the forecasts of leading experts in the oil industry, the main method of developing most oil deposits in the near future remains the method of flooding, as a fairly effective method. However, the accumulated experience of its implementation has shown [14] that it has significant disadvantages, including the following:

1. If heterogeneous and multi-layer objects are developed, it is difficult to achieve the effect of their full coverage by flooding. The above results in the fact that significant volumes of oil reserves are not involved in development.

2. In addition, the rate of production of inhomogeneous reservoirs varies, resulting in premature flooding of highly permeable reservoirs. And in the low-permeable reservoirs that lie together with them, the oil remains unaffected by flooding.

3. An attempt to develop oil reserves that remain in reservoirs that have been flooded is difficult, since the remaining (residual) oil is closed (sealed) by the water that was pumped into the reservoirs.

Let's consider the conditions and state in which residual oil is located in the reservoirs and therefore it is extremely difficult to recover it using conventional technologies (methods) [2]:

A. Occurrence mode. Residual oil by its occurrence mode is characterized by discontinuity of various scales. The scale level varies from individual pores to the level of individual sections of the deposit [3], while for most fields, macro- and micro-levels can be distinguished that characterize the main classes of residual oils $[5,6]$. At the late stage of field development, as shown by the experience of development [4, 7], the following two tasks need to be solved: a) it is necessary to implement into effective development reserves that remained undeveloped; b) active reserves covered by flooding must be fully worked out,

B. State. Residual oil in those zones of reservoirs that are characterized by waterlogging can simultaneously be in such states as:

- film oil, which is adsorbed on the surface of a porous medium (residual oil of the microlevel, represented only in the waterlogged parts of reservoir systems);

- capillary-trapped oil, which is located in a porous medium and is expressed as droplets and globules separated by a film of water from the skeleton of the porous medium [6]. 


\section{Results and Discussion}

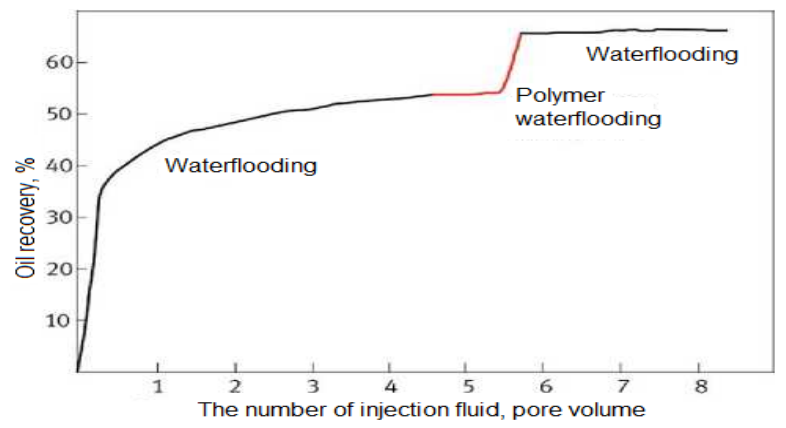

Fig. 1. Oil recovery with polymer flooding after traditional water flooding ([9] по C.H. Gao, 2011)

High degree of macro-heterogeneity of flooded layers and productive horizons propose activation of development systems at operational facilities, their improvement $[2,4,7]$. Among the methods of influence on objects at the final stage of development, a special place is occupied by flow-regulating technologies. Together with modern hydrodynamic methods of increasing oil recovery, they are considered $[9,10]$ as one of the most effective ways to develop oil reserves of highly watered objects (Fig. 1). The use of flow-regulating technologies makes it possible to achieve a noticeable effect by reducing the water content of the extracted products (Fig. 2) and, accordingly, the cost of production (on average, 1.2-2 times). As a result, there is an increase in oil recovery, estimated at 2-15\% [9].

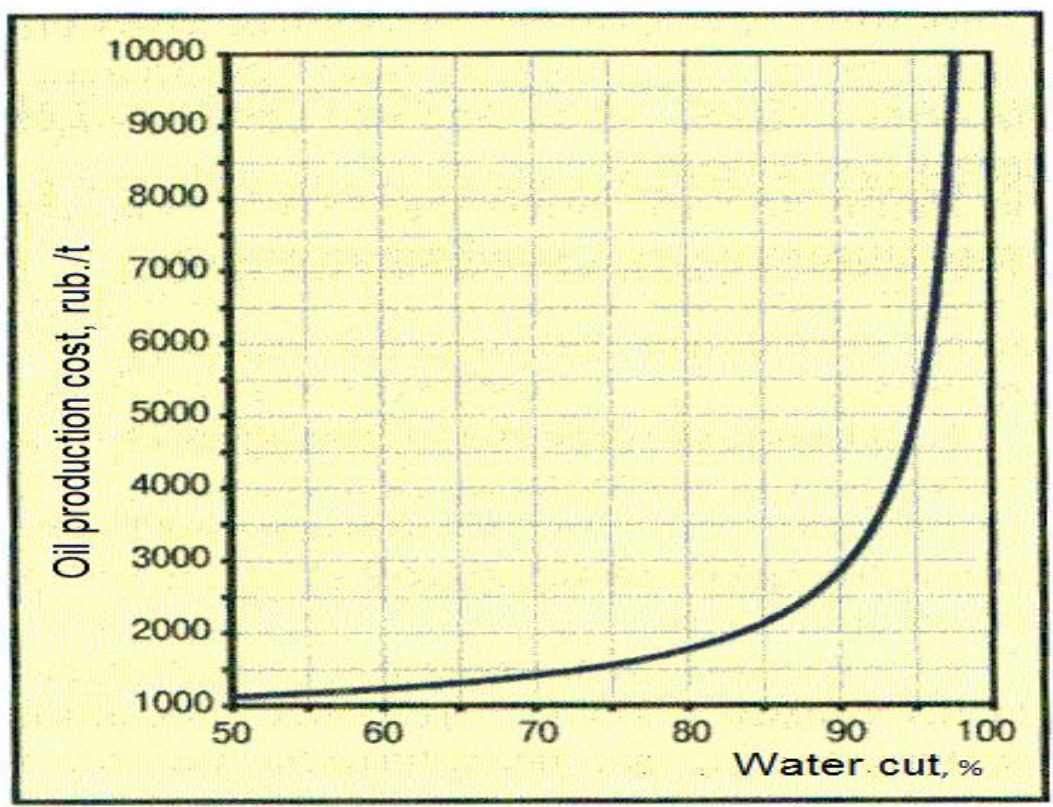

Fig. 2. Dependence of oil production cost on water cut (according to V.E. Stupochenko et al. [9]) 
In order to implement the "Research program for assessment of the effectiveness of oildisplacing compositions and reagents" adopted by Tatneft, it was decided to form several pilot sites at the Romashkinskoye deposit [8]. Each of them was a reversed five-point element with sandstone strata already partially submerged. Intervals of productive horizons were covered by fiberglass tails (FGT). At two sites of the Romashkinskoye deposit (one on the main, Upper Devonian Deposit - horizon $D_{\text {I }}$ of the Minnibaevskaya operational area, the other one on Deposit \# 5 of the Radaevian-Bobrikovian horizons of the Mississippian period (Fig. 3, 4) a series of experiments were conducted under conditions of high-capacity, relatively homogeneous reservoir porosity and permeability (table 1). The first site is a twolayer object, and the second one is a single-layer object. Production of residual oil reserves was carried out first by flooding with untreated water to an irreducible oil saturation, and then by pre-displacement of oil using flow-regulating technology.

In connection with the above, the issues of improving control over flooding of those heterogeneous productive layers located in the "old" oil-producing regions are being updated. If we take the Ural-Volga region as an example, we can note that in this macroregion, since the end of the 70s, wells have been used in which fiberglass tails (FGT) are used as production columns in the range of productive horizons. New technologies proposed by specialists of the institute "VNIIneftepromgeophysics" (now PJSC SRF "Geofizika") are based on the use of contactless methods of high-frequency electrometry in wells. Their use in the process of oil reserves development allows to give a quantitative assessment of the oil saturation (current and residual) of reservoir layers as a whole, and individual interval. The induction logging method (IM) is used both in observation (used as a control) and in production and injection (working) wells [11]. The data obtained as a result of interpretation of the induction method diagrams on the $\mathrm{D}_{\mathrm{I}}$ horizon section made it possible to estimate the parameters of oil reserves production in the zone located at an average distance of $1.5 \mathrm{~km}$ from injection wells [8]. As it turned out, even in the conditions of areal distribution of high-capacity reservoirs with stable values of layers' thickness, low surface efficiency ratios are achieved-about 0.60 0.62. At the same time, in certain intervals of productive formations, the production of reserves, determined by the displacement efficiency, exceeds $61 \%$.
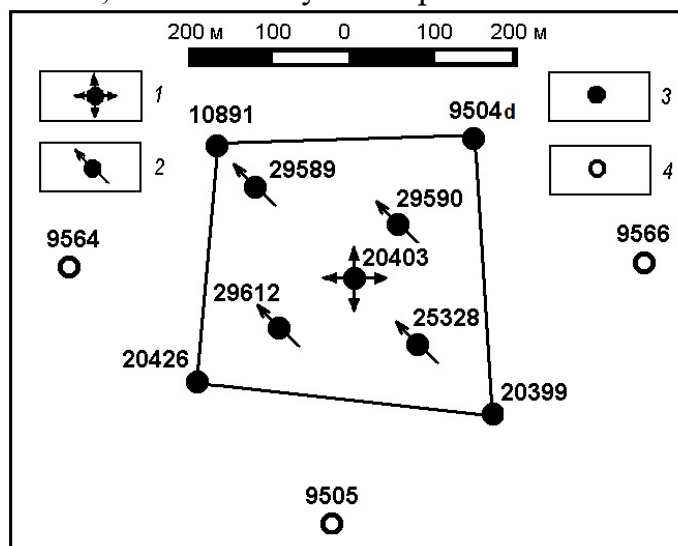

Fig. 3. Layout of wells at the experimental site with FGT at the Minnibaevskaya site, horizon DI.

Wells: 1, 2, 3 - injection, control and extracting with FGT, respectively; 4-extracting with conventional design

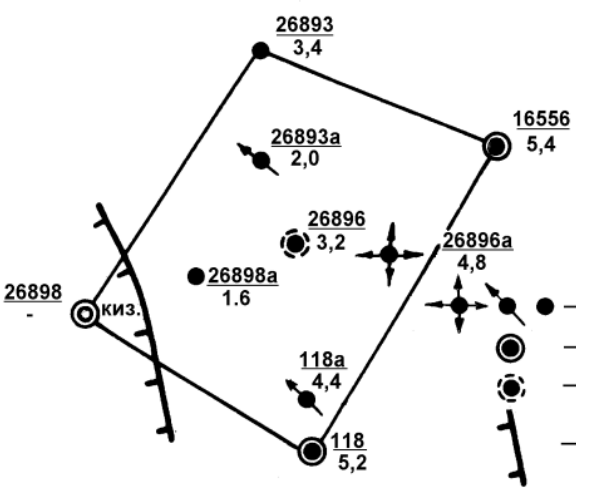

Fig. 4. Map of effective oil-saturated thicknesses of the experimental site with FGT, Deposit \# 5 (scale 1:6000).

Wells: 1 - injection, control and extracting with FGT, 2 - extracting without FGT, 3 - extracting with FGT above the productive horizon, 4 - reservoir replacement line $\mathrm{BbI}^{3}$. Numbers near wells: number in the numerator, thickness in the denominator, $m$ 
Table 1. Filtration and capacitance properties of layers of the experimental site of the horizon $\mathrm{D}_{\mathrm{I}}$

\begin{tabular}{|c|c|c|c|c|c|}
\hline \multicolumn{3}{|c|}{ Layers } \\
\hline $\begin{array}{c}\text { porosity, } \\
\%\end{array}$ & $\begin{array}{c}\text { bound } \\
\text { water, } \%\end{array}$ & $\begin{array}{c}\text { permeability, } \\
\text { micron }^{2}\end{array}$ & porosity, \% & $\begin{array}{c}\text { bound water, } \\
\%\end{array}$ & $\begin{array}{c}\text { permeability, } \\
\text { micron }^{2}\end{array}$ \\
\hline $21.5 / 135$ & $5.5 / 135$ & $1.090 / 135$ & $22.1 / 98$ & $5.4 / 98$ & $0.953 / 98$ \\
\hline
\end{tabular}

Note: number of samples is in denominator

At the second stage of experiments (after the creation of a water flooding center on the experimental site and injection of subsurface water in the volume of 220 thousand $\mathrm{m}^{3}$, or on average about 20 thousand $\mathrm{m}^{3}$ per $1 \mathrm{~m}$ of productive section), the IM data confirmed the achievement of a minimum residual oil saturation in the reservoirs opened by the injection well. Close values of reserves extraction (up to the maximum possible - 72-74\%) were also found in the most permeable layers of control wells. If oil recovery was estimated at $42 \%$ for the period of pilot site drilling, then the use of two factors - organization of a new flooding center (which in itself serves to intensify oil production) and multiple increase in well grid density - led to: firstly, increase in the coverage of reservoirs by flooding by 12 points [8]; secondly, noticeable decrease in the electrical resistivity in adjacent intervals with waterlogged layers.

To evaluate the results of using flow-controlled technologies in a highly watered layer with high-capacity reservoirs, a oxyethylcellulose (OEC) slug of natrasol-250 brand HHR-P $1 \%$ concentration of $2043 \mathrm{~m}^{3}$ of water $(20 \mathrm{t}$ ) was injected into injection well 20403 in mid1995. Induction logging was performed in the injection and control wells in the monitoring mode after pumping the following volumes of bottom water $-500,1500$ and $500 \mathrm{~m}^{3}$. According to IM research on layer "b", the flood coverage rate increased from 0.89 to 0.96 (Fig. 5). Along with this, a decrease in the residual oil saturation of the "b" layer was recorded from $30-32$ to $21-25 \%$. As expected, according to the research of control wells, water flooding of layer intervals with slightly worse reservoir properties was established. With traditional flooding, even with a dense grid of wells, they remained poorly covered by water displacement. Another fact draws attention to itself: the change in oil saturation in the smaller side of those intervals that were previously most washed with pumped untreated water. The combined effect of these two processes was shown in the form of a significant increase in oil production (Fig. 6).

So, the use of technology of flooding control using the induction method in wells of special design confirmed the effect of flooding with a thickened displacing agent. In this case, this is observed in conditions of reservoir saturation with low-viscosity oil - 4.5 MPa $\cdot \mathrm{s}$ in layer conditions. Interpretation of IM diagrams in four control wells allowed to establish that surface efficiency ratio increased for layers " $b$ " and " $\mathrm{d}_{2+3}$ " from 0.65 and 0.64 to 0.70 and 0.74 , respectively. 


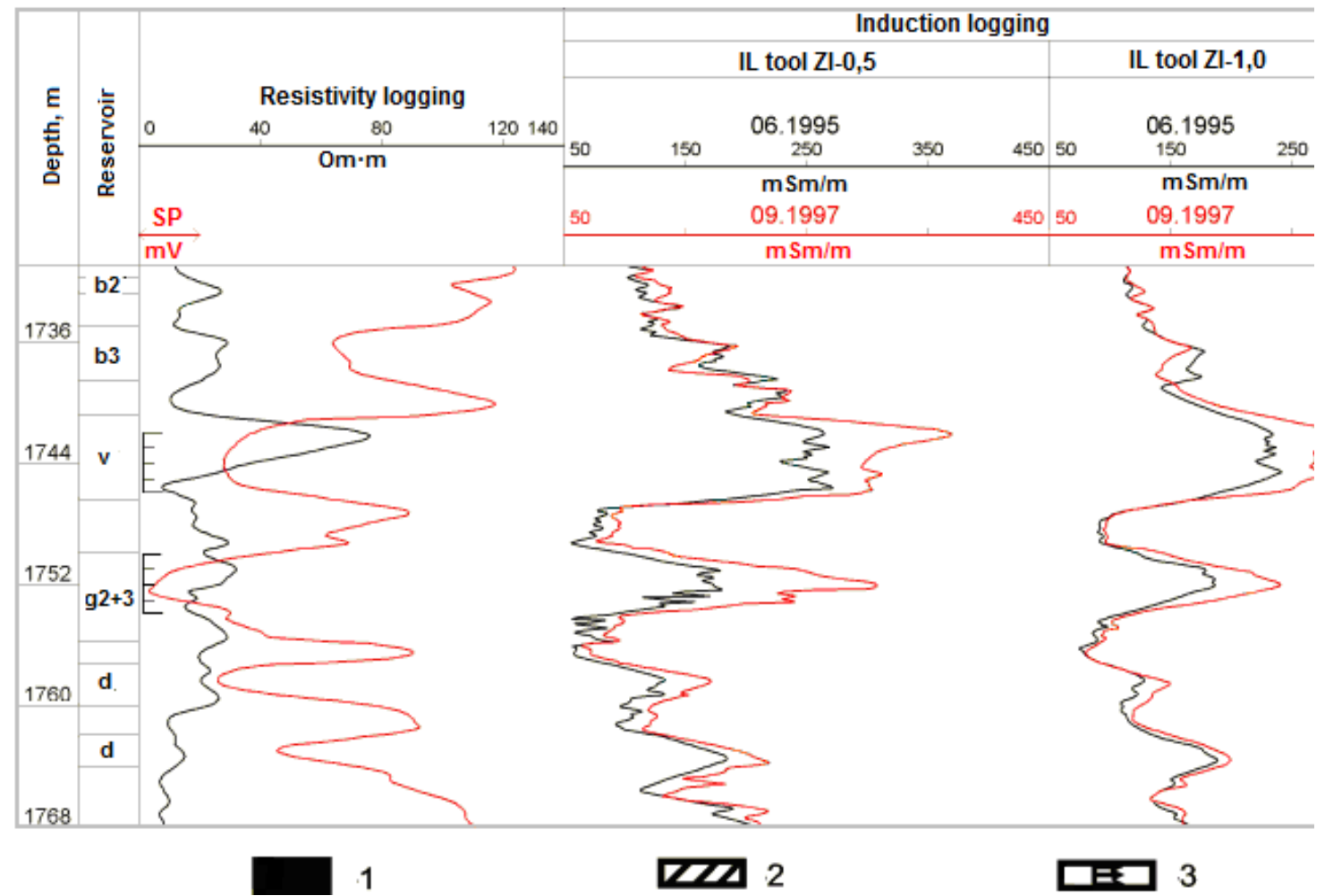

Fig. 5. Dynamics of layers flooding in the injection well 20403 according to IM data (measurements from 06.1995 and 09.1997) (according to V.I. Dvorkin).

Intervals: 1 -oil-saturated, 2 - waterlogged, 3 - perforated.

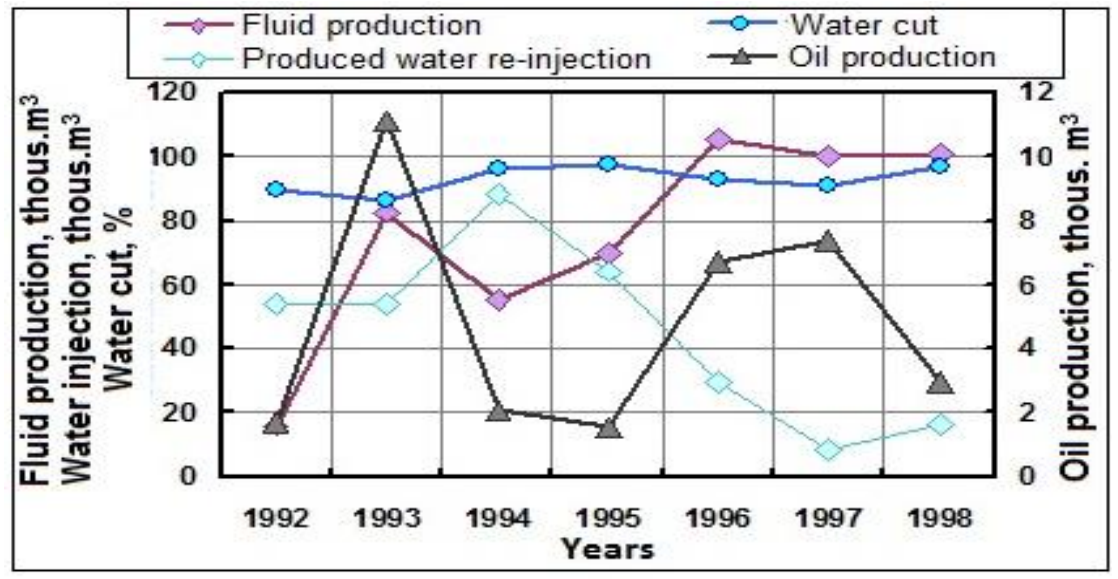

Fig. 6. Main indicators of the experimental section development of the horizon $\mathrm{D}_{\mathrm{I}}$

Studies in injection well 20403 showed that the injection of the OEC slug resulted in decrease in the residual oil saturation of the layer " $v$ " from 28.4 to $23.2 \%$. This indicates that the maximum value of the oil displacement coefficient by water $(0.72)$ obtained as a result of laboratory studies was exceeded by 3.4 points. Similar phenomena are also typical for layer sections of three control wells out of four. Obviously, due to the distribution of filtration 
flows in well 25328 in the waterlogged part of the reservoir "b", the minimum values of residual oil saturation, which were reached during normal flooding and amounted to $38-41 \%$, decreased only to $30 \%$ (Fig. 7).

At the experimental site of the Deposit \# 5 with super-dense wells placement (about 3 ha/well based on two control wells and one injection well) the minimum values of residual oil saturation were achieved in 3.5 years [8]. Due to stationary injection in the bottom-hole zone of the injection well, mobile oil was displaced throughout the production interval (Fig. 8). The remaining oil saturation decreased to an average of $45.3 \%$. This corresponds to an oil recovery of $49 \%$. However, in control wells (reminder, they are located at a distance of $100 \mathrm{~m}$ and $160 \mathrm{~m}$ from the source of flooding), only 50-55\% of the layer thickness is covered by active displacement. The achieved oil recovery according to the results of the research is estimated at $33-41 \%$ (with a decrease in oil saturation to $51.7-58.3 \%$ ). Despite relatively high indicators of current oil saturation of the layer, significant water-logging of extraction wells does not allow them to be operated cost-effectively.

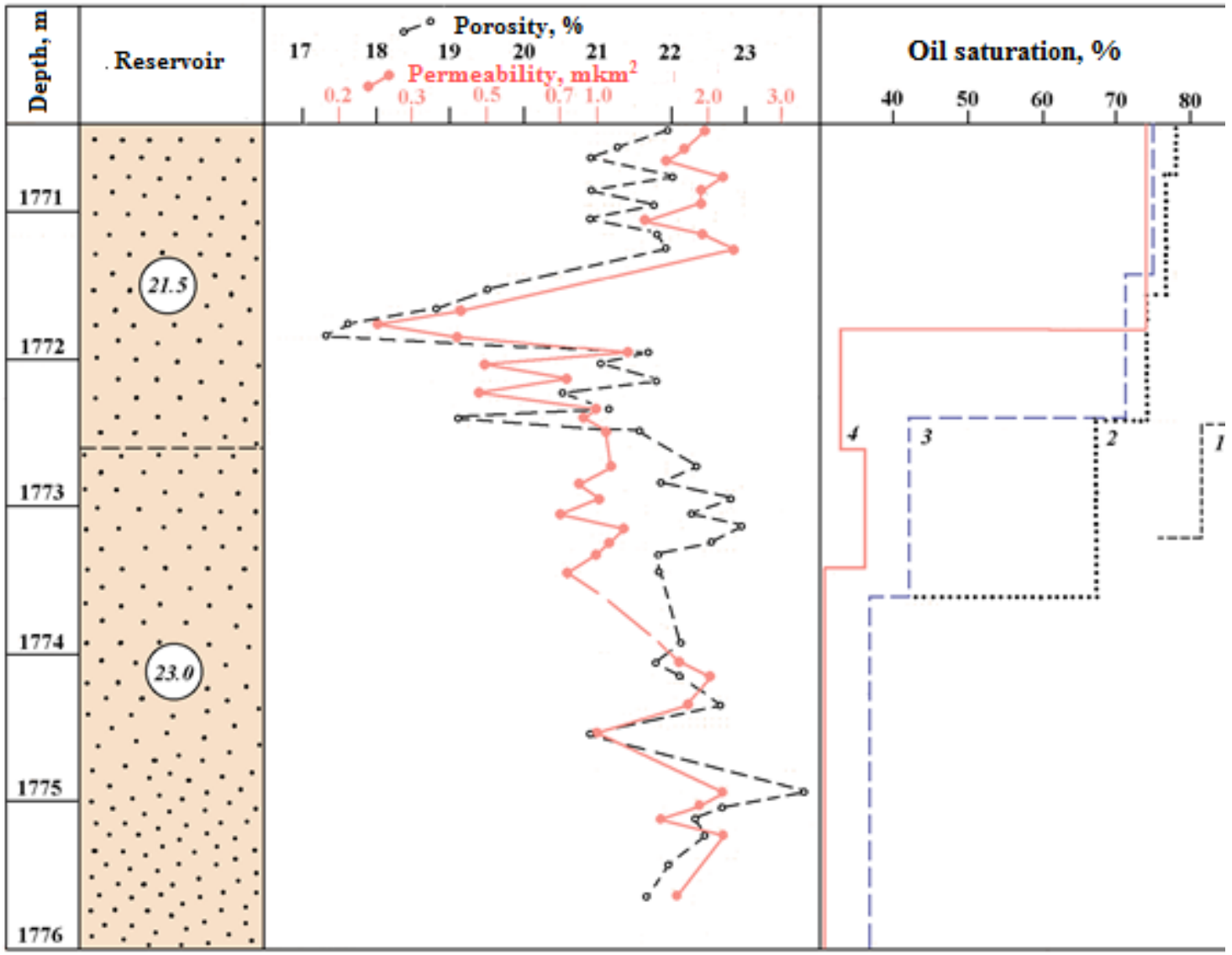

Fig. 7. Core diagram and dynamics of oil saturation in the layer section "v" of the horizon $D_{I}$ in the cor well 25328 of Minnibaevskaya experimental site.

Oil saturation by IM: 1 - from 11.1991 (after cementing the casing), 2 - from 09.1992, 3 - from 11.1994 (after normal flooding, Kcov - 0.64), 4 - from 09.1997 (after OEC injection). In circles porosity according to GIS. 
At the experimental site of the Deposit \# 5 of the Romashkinskoye deposit with an oil viscosity of about $30 \mathrm{MPa} \cdot \mathrm{s}$, the effect of both ordinary water and thickener of the displacing agent was observed similar to the layers " $\mathrm{v}$ " and " $\mathrm{g}_{2+3}$ " of the $\mathrm{D}_{\mathrm{I}}$ horizon. The productive layer $\mathrm{BB}_{1}^{3}$, as well as the Devonian strata discussed above, is represented by quartz sandstones with a porosity of 18.4 to $24.2 \%$ (on average $22.6 \%$ ). The initial sub-stages of the experiment are described in detail in paper [8]. In contrast to the " $v$ " and " $\mathrm{g}_{2+3}$ " layers of the Devonian, studies of drilled wells have shown that only two wells (\#\# 118a and 26898a) show the initial phase of flooding. The data of the performed IM study allow to assert that with the traditional grid density of wells (about $16 \mathrm{ha} /$ well) and with normal flooding, the coverage of the layer by the impact in the inter-well space of the layer at this site of experimental work is only 10.4 $\%$ (40\% in area and $26 \%$ in thickness) [8]. This means that even in the conditions of an area of high-capacity layer, saturated with high-viscosity oil, the oil recovery laid down in the projects is practically not achievable.

IM measurements after flooding of the productive layer with a reagent containing 15 tons of thickener in the form of OEC showed a decrease in the residual oil saturation to $36.3 \%$ in the bottom-hole zone of the injection well 26896a. Based on oil recovery, this corresponds to $59.0 \%$, or an increase of 10 points. Attention is drawn to the change in the nature of the layer water cut in the control well 118a. As of the date of layer opening by drilling, the water cut was recorded only in the range of $1161.0-1162.4 \mathrm{~m}$, and after injection of the reagent, additional intervals of 1159.4-1160.0 m, 1160.2-1160.4 m, 1160.8-1161.2 $\mathrm{m}$ and 1161.6$1162.4 \mathrm{~m}$ were covered by displacement. This was a reflection of the redistribution of filtration flows in the layer, which affected the growth of layer coverage by flooding.

Studies on physical area models of the layer and computational experiments for flooding elements [12] also prove that the mechanism of polymer flooding is aimed at covering the oil displacement from different-sized pore channels, that is, it also acts at the level of microuniformity of the porous medium. Therefore, flooding with the OEC slug allows to count on a double and even synergistic effect. Moreover, according to N.N. Mikhailov, it is possible to further wash the film oil, some of which can be extracted under the influence of ordinary water: this is possible if sections of the rock skeleton form through channels covered with oil film. The latter is characteristic of hydrophobic reservoirs or with intermediate wettability [3]. 
Injection well $26896 \mathrm{a}$

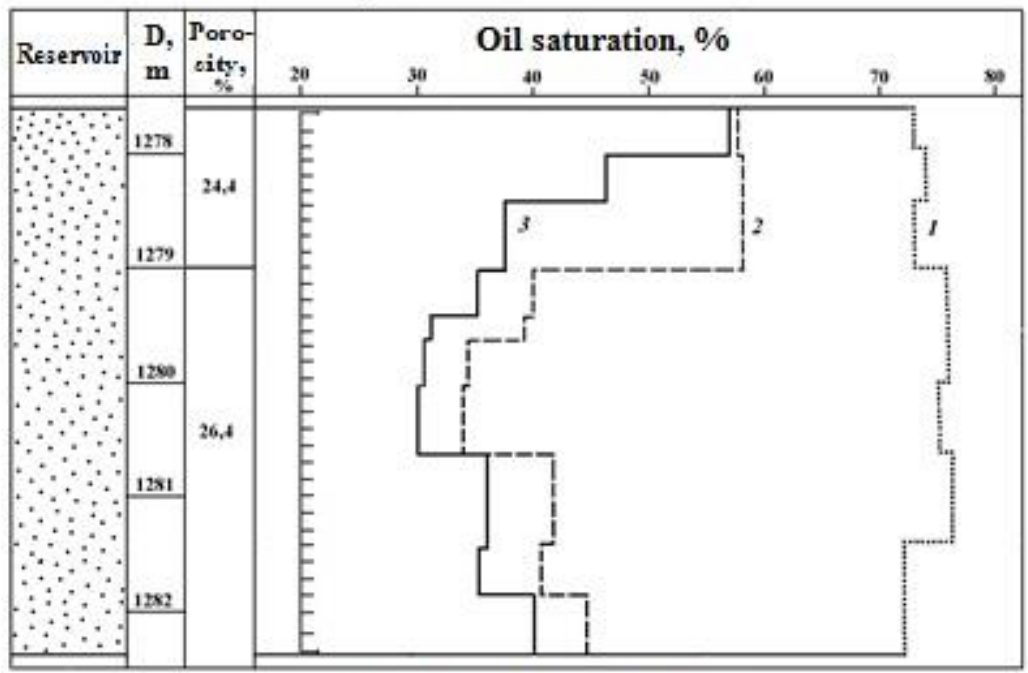

Observation well 118a

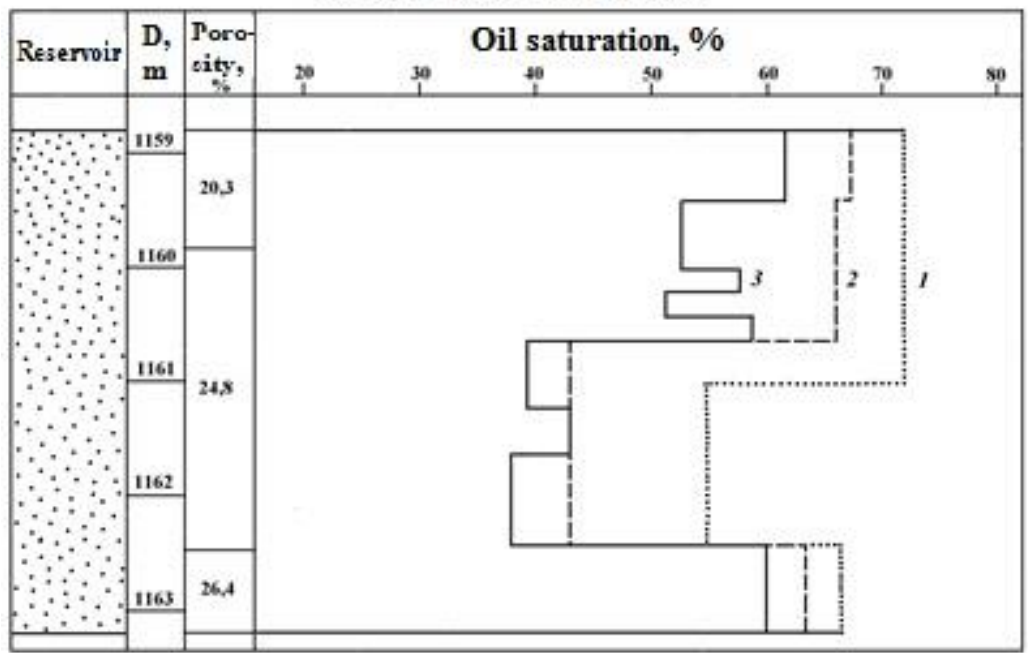

Fig. 8. Dynamics of changes in oil saturation of reservoirs in the wells of the experimental section of the Deposit \# 5.

Measurements in well 26896a: 1 - from 11.1991, 2 - from 12.1995, 3 - from 10.1996; measurements in well 118a: 1 - from 05.1991, 2 - from 06.1994, 3 - from 06.1996 (1 - after drilling, 2 - achievement of undiminished oil saturation during normal flooding, 3 - after OEC slug injection)

In favor of the presence of mobile residual oil in the inter-well space of high-capacity layers of the areal type of development, the technological and economic efficiency of side shafts drilling at objects being at the final stage of development testifies. One of these examples is given in paper [13] based on the analysis of the extraction capabilities of the side shafts of one of the deposits of a highly productive (porosity of $27 \%$, average permeability $0.621 \mathrm{~mm}^{2}$ ) BS1 layer in the Surgut arch. The cutting of the side shafts was performed at a high (about $95 \%$ ) water content of the wells products of the main fund and at achieved well grid density of $23 \mathrm{ha} /$ well. With an average working time of about 6 years, the average accumulated extraction per well is 26.8 thousand tons. It should be noted that almost half of 
the oil produced in the BS1 layer under consideration in recent years has been provided by the operation of side wells.

\section{Conclusions}

According to established believes, it is considered that high efficiency of chemical EOR can be achieved by using compositions that increase both the coverage of flooding and the displacement coefficient, in particular, polymers and surfactants $[14,15]$. The experience of using such compositions, in particular, is summarized by specialists of OGPD "Bavlyneft" [16]. It is of interest to use the technology of the TatNIPIneft Institute, created on the basis of cellulose esters and non-ionic surfactants. Analysis of the application of this composition showed that the current specific technological effect was 2610 tons per well-treatment. At the same time, the reagent consumption per operation was $7.0 \mathrm{t}$ of oxy-ethylcellulose of the "Sulfacell" brand and $0.7 \mathrm{t}$ of non-ionic surfactant of the "Neonol AF 912" brand. Expenses in total amounted to an average of 920 thousand rubles (prices of 2006) (Fig. 9) According to the authors of the study, the high cost of this technology implementation is objectively a deterrent to the application of compositions using surfactants.

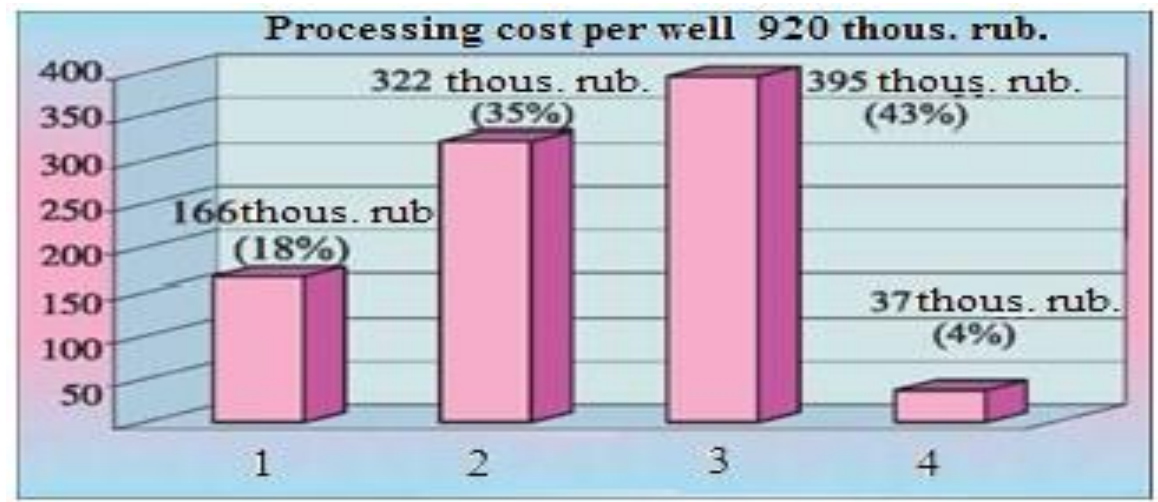

Fig. 9. Cost structure for the implementation of EOR technology using composite systems based on cellulose esters and non-ionic surfactants (according to R.M. Shakirov et al. [16]): 1 - first and final workings, 2 - chemical agents, 3 - injection, 4 - technical maintenance

Thus, polymer based thickeners of exhaust agents are the alternative to the use of composite chemical EOR, containing expensive surfactants. Along with the increase in layer coverage by flooding (which was initially targeted by flow-regulating technologies), there is also a displacement of part of the capillary-trapped oil in the already flooded layer intervals. This is a strong argument in favor of using this tertiary method to increase oil recovery, including in conditions of high waterlogging of development facilities, at the final stage of development.

\section{References}

1. N.N. Lisovsky, M.M. Ivanova, V.F. Baziv, V.A. Malyugin, Improving the development of oil deposits in the final stage, Methods for improving the efficiency of oil deposits development in the final (fourth) stage, 5-19 (Moscow: NP NAEN, 2008)

2. M.L. Surguchev, A.T. Gorbunov, D.P. Zabrodin, et al., Methods of residual oil extraction, 347 (Moscow: Nedra, 1991)

3. N.N. Mikhailov, Oil Industry, 11, 14-17 (1997) 
4. R.Kh. Muslimov, Modern methods of managing oil field development using flooding, 596 (Kazan: KSU Publishing house, 2003)

5. V.I. Titov, S.A. Zhdanov, Oil Industry, 8, 26-28 (1988)

6. N.N. Mikhailov, The residual oil saturation of the producing layers, 270 (Moscow: Nedra, 1992)

7. R.G. Abdulmazitov, Oil Industry, 8, 104-107 (2003)

8. R.Z. Mukhametshin. Geological bases of effective development and extraction of hardto-recover oil reserves, 538 (Kaliningrad,2006)

9. V.E. Stupochenko, A.Ya. Sorkin, V.A. Kan et al., Oil Industry, 11,48-51 (2005)

10. Victor P. Telkov, Masoud G. Mostajeran, Exposition. Oil. Gas, 4 (64), 52-55 (2018)

11. V.G. Dvoretsky, B.M. Orlinsky, V.V. Trufanov, R.Kh. Muslimov, Oil Industry, 8, 21-24 (1986)

12. A.N. Chekalin, G.V. Kudryavtsev, V.V. Mikhailov, Study of two-and three-component filtration in oil layers, 148 (Kazan: Publishing house of Kazan University,1990)

13. D.N. Lutfullin, R.Z. Mukhametshin, Assessment of technological efficiency of methods for pre-development of high-water layer reserves // Innovations in the exploration and development of oil and gas deposits. 2. 178-181. (Kazan: Ikhlas Publishing house, 2016)

14. R.Kh. Almaev, Oil Industry, 12, 22-24 (1993)

15. Sh.F. Takhautdinov, R.S. Khisamov, A.S. Sultanov et al., Oil Industry, 7, 26-28 (2009)

16. R.M. Shakirov, R.M. Vildanov, R.Z. Rizvanov et al., Georesursy, 3(20), 45-47 (2006) 